\title{
Epithelioid hemangioendothelioma: an overview and update on a rare vascular tumor
}

\author{
Angela Sardaro, ${ }^{1}$ Lilia Bardoscia, ${ }^{1}$ Maria Fonte Petruzzelli, ${ }^{1}$ Maurizio Portaluri2,3 \\ ${ }^{1}$ Department of Interdisciplinary Medicine, Section of Diagnostic Imaging and \\ Radiotherapy, University Aldo Moro, Bari; ${ }^{2}$ Department of Radiotherapy, A. Perrino \\ Hospital, Brindisi; ${ }^{3}$ Clinical Physiology Institute, National Research Council (IFC-CNR), \\ Pisa-Lecce, Italy
}

\begin{abstract}
Epithelioid hemangioendothelioma is a rare vascular tumor, described for the first time in 1975 by Dail and Liebow as an aggressive bronchoalveolar cell carcinoma. The etiology is still a dilemma. Studies about suggestive hypothesis are ongoing. Most of the times it affects lung, liver and bones, although this kind of tumor may involve the head and neck area, breast, lymph nodes, mediastinum, brain and meninges, the spine, skin, abdomen and many other sites. Because of its heterogeneous presentation, as it represents less than $1 \%$ of all the vascular tumors, it is often misdiagnosed and not suitably treated, leading to a poor prognosis in some cases. Over $50-76 \%$ of the patients are asymptomatic. A small number of them complains respiratory symptoms. Bone metastases might cause pathological fractures or spine compression, if they arise in vertebrae. Imaging is necessary to determine morphological data, the involvement of surrounding tissues, and potentially the cleavage plan. It is important to recognize the
\end{abstract}

Correspondence: Lilia Bardoscia, Dipartimento Interdisciplinare di Medicina - Sezione di Diagnostica per Immagini e Radioterapia, AOU Policlinico di Bari, Piazza Giulio Cesare 11, 70124 Bari, Italy.

Tel.: +39.340.8233273.

E-mail: liliabardoscia@gmail.com

Key words: bone metastases, endothelial markers, epithelioid hemangioendothelioma, radiation therapy, vascular tumor, pulmonary nodules.

Acknowledgments: the authors acknowledge Alison Frank for assisting in revising and editing the English manuscript.

Contributions: LB literature review and manuscript drafting; AS, MFP, manuscript critical revising; MP, work supervision and general support. All authors read and finally approved the version to be submitted.

Conflict of interests: the authors declare no potential conflict of interests.

Received for publication: 7 July 2014.

Revision received: 18 September 2014.

Accepted for publication: 30 September 2014.

This work is licensed under a Creative Commons Attribution NonCommercial 3.0 License (CC BY-NC 3.0).

(C) Copyright A. Sardaro et al., 2014

Licensee PAGEPress, Italy

Oncology Reviews 2014; 8:259

doi:10.4081/oncol.2014.259 expression of vascular markers (Fli-1 and CD31 are endothelial-specific markers), and the microscopic evidence of vascular differentiation to make a correct diagnosis, as many pulmonary diseases show multiple nodular lesions. Because of its rarity, there is no standard for treatment. We focused on radiotherapy as a good therapeutic option: despite the poor prognosis, evidence is in favor of radiotherapy which offers local pain control with good tolerance and better quality of life at least at a one-year follow-up in most of cases. Further studies are needed to establish the standard radiation dose to be used for locoregional control of such a complex and extremely rare disease.

\section{Introduction}

Epithelioid hemangioendothelioma (EHE) is a rare vascular tumor with an epithelioid and histiocytoid appearance, originating from vascular endothelial or pre-endothelial cells. It represents less than $1 \%$ of all vascular tumors and was described for the first time in 1975 by Dail and Liebow as pulmonary EHE (P-EHE). ${ }^{1}$ Initially, it was believed to be an aggressive form of bronchoalveolar cell carcinoma, invading adjacent blood vessels and small airways, hence the name intravascular bronchioloalveolar tumor. ${ }^{2-4}$

The term epithelioid hemangioendothelioma was introduced in 1982 by Weiss and Enzinger to describe a vascular tumor of bone and soft tissue showing features between hemangioma and angiosarcoma.,6 Corrin et al. demonstrated the presence of tumor cells deriving from a lineage capable of differentiation along endothelial lines by using immunohistochemical techniques. ${ }^{7}$ Later, Weldon-Linne et al. confirmed these findings using electron microscopy and revealed a diffuse cytoplasmic staining of the malignant cells with a factor VIII-related antigen. ${ }^{8}$

The recent World Health Organization (WHO 2002) classification describes EHE as lesions that fall into the category of locally aggressive tumors with metastatic potential. ${ }^{9,10}$

The estimated prevalence of EHE is less than one in 1 million. ${ }^{11}$ Due to its rarity, with only approximately 248 cases of P-EHE reported in the current literature, few different groups have published large studies (Amin 93 patients, ${ }^{12}$ Bagan 80 patients, ${ }^{13}$ Kitaichi 21 patients, ${ }^{14}$ Dail 20 patients $^{4}$ ) (Table 1). ${ }^{12-36}$ Clinical registries such as the Armed Forces Institute of Pathology Registry and the International Hemangioendothelioma, Epithelioid Hemangioendothelioma and Vascular Disorders Registry may help in following the natural history of the disease. ${ }^{37}$

The majority of patients were females (male:female 1:4) in most of the studies about P-EHE (Amin 73\%, Bagan 65\%, Kitaichi 62\%, Dail $80 \%$ ), while pleural EHE seems to be more frequent in males. ${ }^{38}$ This malignant vascular tumor usually affects middle-aged patients, 
although cases in children and elderly people have been described. The age of the patients ranges from 7 to 83 years old. ${ }^{15,16}$ The median onset is 36 years old, while the usual age at diagnosis is from 20 to 60 years old. ${ }^{17}$

\section{Etiopathogenesis}

The etiology of EHE is still a dilemma. At the molecular level, different angiogenic stimulators may act as promoters of endothelial cell proliferation. ${ }^{18}$ Recently it has been reported that monocyte chemo-attractant protein-1 is required for EHE proliferation and might promote the development of these lesions by stimulating the angiogenic behavior of endothelial cells. ${ }^{39}$ Budousquie et al. described several clonal abnormalities in tumor cells: a complex unbalanced translocation between chromosomes 7 and 22 with multiple breakpoints, a robertsonian translocation of chromosome 14, and the loss of chromosome Y. ${ }^{40}$ Monosomy for chromosome 11 and thetraploidy have also been detected in a subset of tumor cells. Errani et al. focused on the $\mathrm{t}(1 ; 3)$ (p36.3;q25) mutation: a molecular analysis revealed that CAMTA1 on chromosome 1p36.23 and WWTR1 on chromosome $3 q 25$ are the involved genes. Both genes had previously shown to play important roles in oncogenesis, but it is the first time they are implicated together in a recurrent chromosomal translocation, in EHE. Particularly important is just the lack of CAMTA1 and WWTR1 rearrangements in epithelioid hemangioma, a benign tumor that is often misdiagnosed as EHE. ${ }^{41}$ Recently, Antonescu et al. have found YAP1 rearrangements in most of the transcription factor E3 (TFE3)-rearranged EHEs, and this YAP1-TFE3 fusion subset occurs at the mean age of 30 years showing at least focally, well-formed vascular features and a variably solid architecture. $^{42}$

A new, suggestive hypothesis of the pathogenesis of this disease refers to a causal relationship between chronic Bartonella infection and the development of this rare vascular tumor. The unique Bartonella's capability of invading and inducing long-lasting intraerythrocytic and intraendothelial infections, together with the ability of at least three Bartonella spp. (B. henselae, B. quintana, B. bacilliformis) of inducing vascular endothelial growth factor-mediated vasoproliferation, as they upregulate mitogen and proinflammatory genes resulting in cytoskeletal rearrangement and suppression of endothelial cell apoptosis, suggest that these bacterial pathogens might contribute to the development of vascular tumors. ${ }^{43}$

\section{Occurrence and metastasis}

The Hemangioendothelioma, Epithelioid Hemangioendothelioma And Related vascular Disorders (HEARD) Support Group observed that the most common EHE presentations are liver alone (21\%), liver plus lung $(18 \%)$, lung alone (12\%) and bone alone (14\%) ${ }^{11}$ (Figure 1). However, EHE is a very heterogeneous tumor, and it has been reported to involve many other sites ${ }^{44-56}$ (Table 2). When these cases occur, it may be difficult to determine if the tumor is multicentric or if it is a primary lesion with metastases in other tissues, as EHE may originate in either organ and metastasize to the other or it may have more than one primary site. Sometimes we are able to distinguish metastases from a multicentric primary tumor because of their less differentiation and loss of the expression of epithelial markers. ${ }^{57}$

P-EHE dissemination may occur within blood vessels, lymphatics and pleural cavity. The lung airspaces spread is continuous. Distant hematogenous metastases have been reported mainly in the liver but also in the skin, serosa, spleen, tonsils, retroperitoneum and kidney; colonic metastases have also been described, but they are very rare..$^{58}$
Bone metastases are doubtless the most frequent and the most clinically severe. According to World Health Organization (WHO) classification of Tumors of bone and soft tissues (2002), one half to two thirds of them originates from a vessel (such as a small vein). Exceptionally it may originate from a large vein or artery. ${ }^{59}$

\section{Clinical aspects}

The clinical aspects of P-EHE are summarized in Table 1. P-EHE is often incidentally diagnosed and over $50-76 \%$ of patients are asymptomatic, usually detected by abnormal chest radiography during health examinations, or they have only minor, aspecific symptoms at the time of the diagnosis. Otherwise, respiratory symptoms together with chest pain or pleuritic pain are typical at P-EHE detection, even if few patients may complain alveolar hemorrhage, hemoptysis and anemia, occasionally clubbing and weight loss. ${ }^{12-14,20}$ Table 3 summarizes the clinical aspects of EHE localized at other sites, different from lung: the clinical presentation of this rare vascular tumor is as heterogeneous as its clinical localization can be. . $10,47,49,51,53-58,60-69$ In particular, when bone metastases of EHE involve more than $50 \%$ of the cortex, there is a serious risk for pathological fractures, and if they arise in vertebrae they might cause spine compression and therefore paresthesia, loss of muscular strength and paraplegia. ${ }^{57,60,61}$ Hemolytic anemia and consumption coagulopathy have been rarely described. Usually, male PEHE patients tend to be detected more frequently by subjective symptoms (50\%) than females (8\%). ${ }^{11}$

\section{Diagnostic tools}

\section{Laboratory data}

Blood counts are usually normal. There is no effect on the total white blood cell count, erythrocyte sedimentation rate or serum proteins, but several values might abnormally increase if the liver is involved: white blood cell count, serum alkaline phosphatase, aspartate aminotransferase, gammaglutamyl transferase, amylase and lipase. ${ }^{63}$ Chemistry profiles and urinalyses are generally normal.

\section{Radiological findings}

The imaging evaluation of the EHE must be as complete as possible. The radiology examination and magnetic resonance imaging (MRI) are necessary to obtain morphological data: the degree of the neoformation, the relations with the surrounding tissues, a potential cleavage plan. ${ }^{61}$

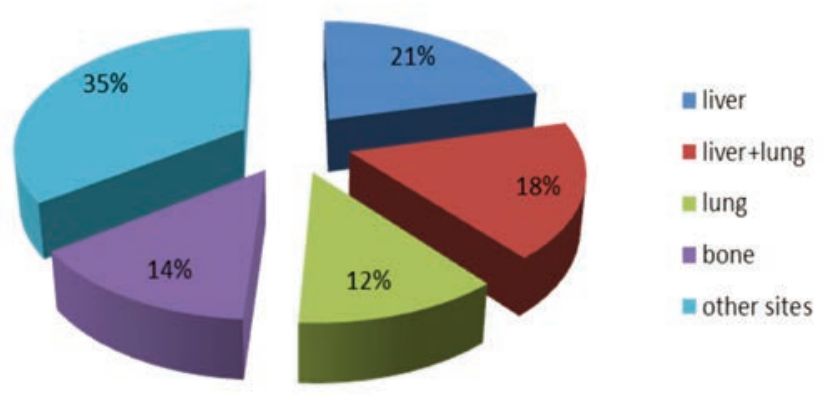

Figure 1. The most common epithelioid hemangioendothelioma presentations. 







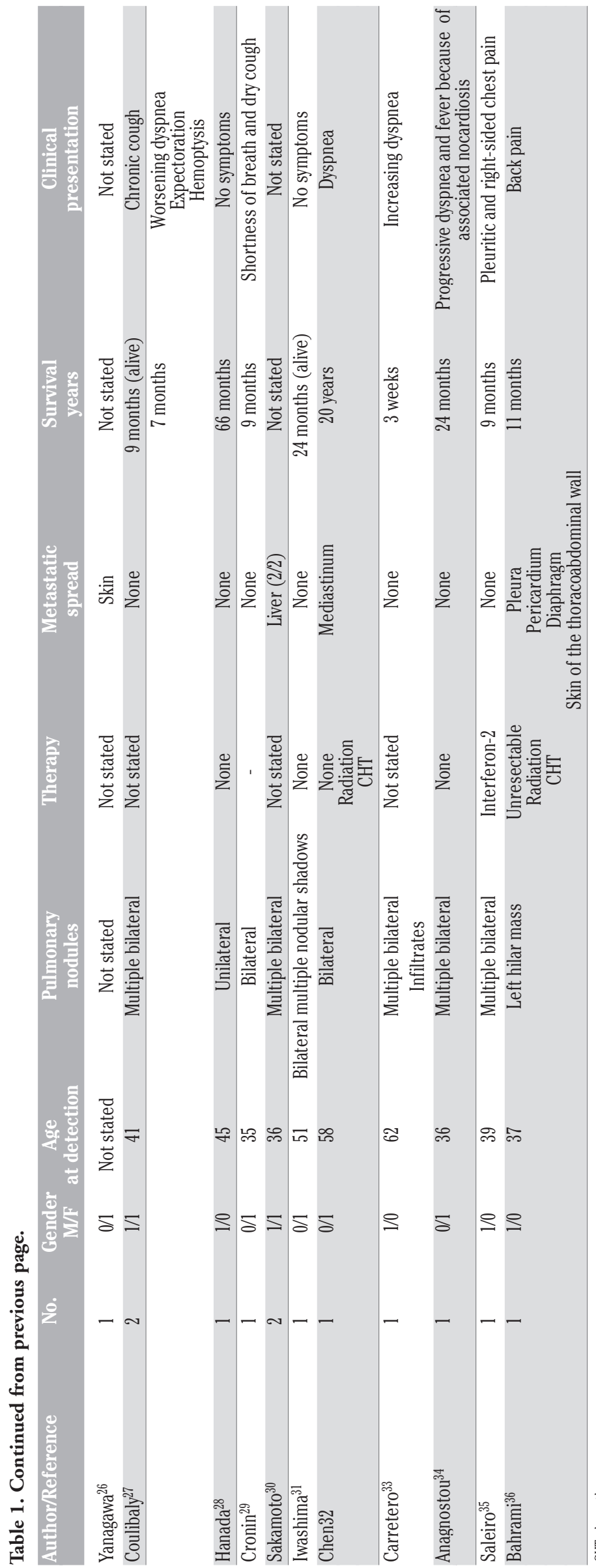

P-EHE radiologically appears as multiple perivascular nodules with well-defined or blurred margins in both lungs, showing little or no growth on serial chest radiographs or computed tomography (CTs). The nodules may range in size up to $2 \mathrm{~cm}$, but most are less than $1 \mathrm{~cm}$ in diameter and are predominantly in the lower parts of the lungs. They are usually found at small and medium sized vessels and bronchi. Bilateral multiple nodular opacities are the most common presentation: about $60 \%$ of cases display these changes, even if P-EHE occasionally develops as a solitary, lung nodule, measuring up to $5 \mathrm{~cm}\left(10-19 \%\right.$ of case $\left.^{13}\right)$. Hilar lymph node enlargement, lymph node metastases, interlobular septal thickening and pleural effusions can be also noticed, as well as unilateral opacities and mosaic areas of ground-glass attenuations. Radiologic calcification is not common but histologic examinations often reveal calcified and ossified necrotic centers of the nodules. ${ }^{29}$

Bone metastases appear as osteolytic lesions with homogeneous contrast enhancement on X-ray and CT scan, without matrix mineralization; osseous expansile remodeling may be seen, and joint invasion is also a common feature. These lesions can be localized in the cortical or medullary bone: cortical disruption and extension into the soft tissue can be present, so soft tissue swelling might be radiologically observed in this case. Periosteal reaction is rare in the absence of pathologic fracture, instead, as well as calcification. There is no specific pattern of signal intensity at MRI imaging. Most frequently EHE shows low to intermediate signal intensity on T1-weighted images and high signal intensity on T2-weighted images, together with homogeneous enhancement after the injection of contrast medium. ${ }^{60}$

Ultrasonography emphasizes the tumor's vascularization and allows differential diagnosis vis-à-vis an arteriovenous malformation or even an aneurysm. ${ }^{61}$

In some cases, positron emission tomography ${ }^{17}$ and bone scintigraphy are used to evaluate lesions at other sites. Increased uptake of F-fluorodeoxyglucose in this tumor has been recently reported. ${ }^{70-72}$

Table 2. Other sites of epithelioid hemangioendothelioma presentations.

\section{Site}

Head and neck

Breast

Lymph nodes

Mediastinum

Diaphragm

Brain and meninges

Mastoid

Infundibulum

Clivus

Cerebellopontine angle

Spine

Skin

Peritoneum

Stomach

Retroperitoneum

Ovary

Prostate

Eyelid 


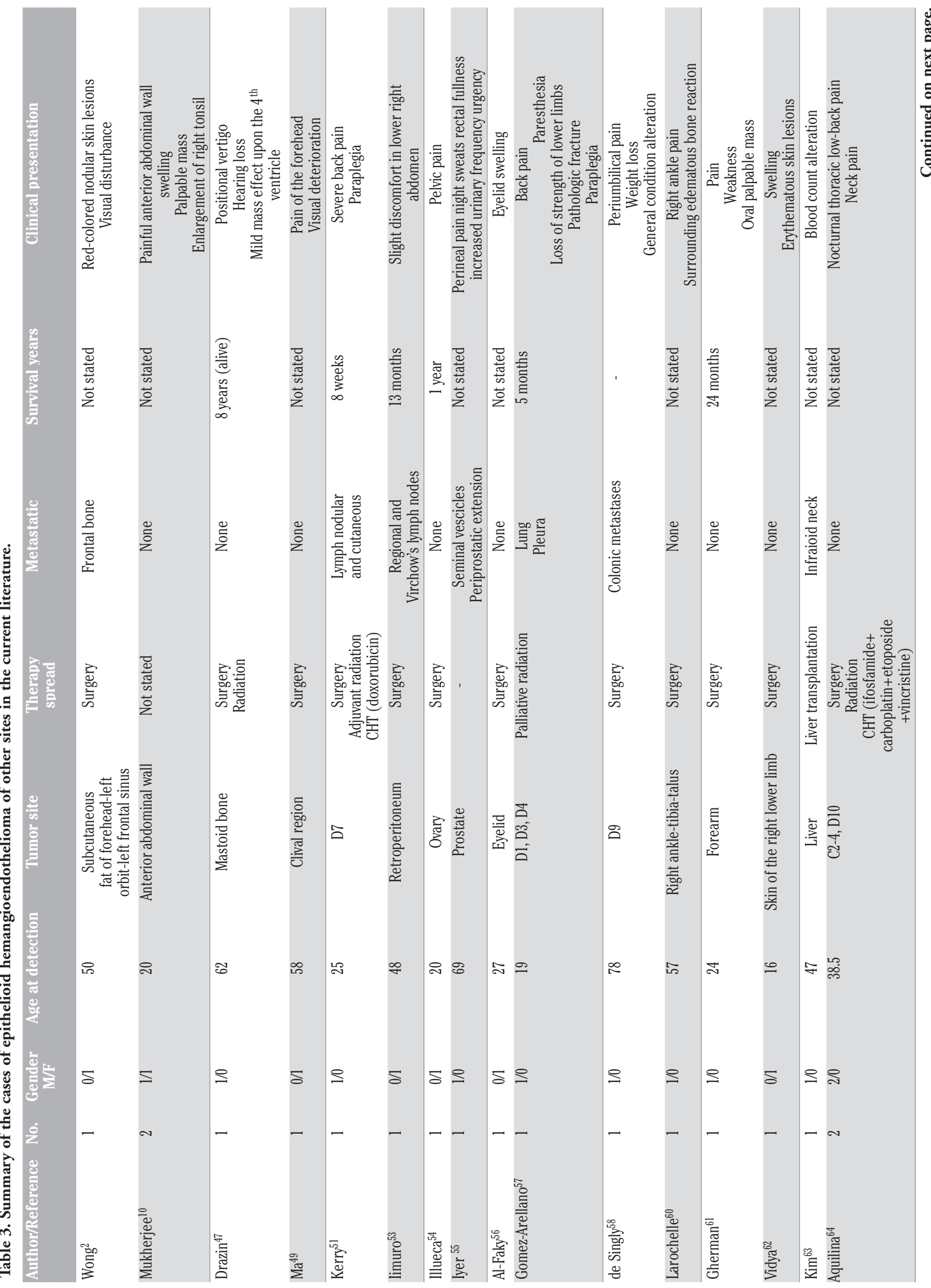




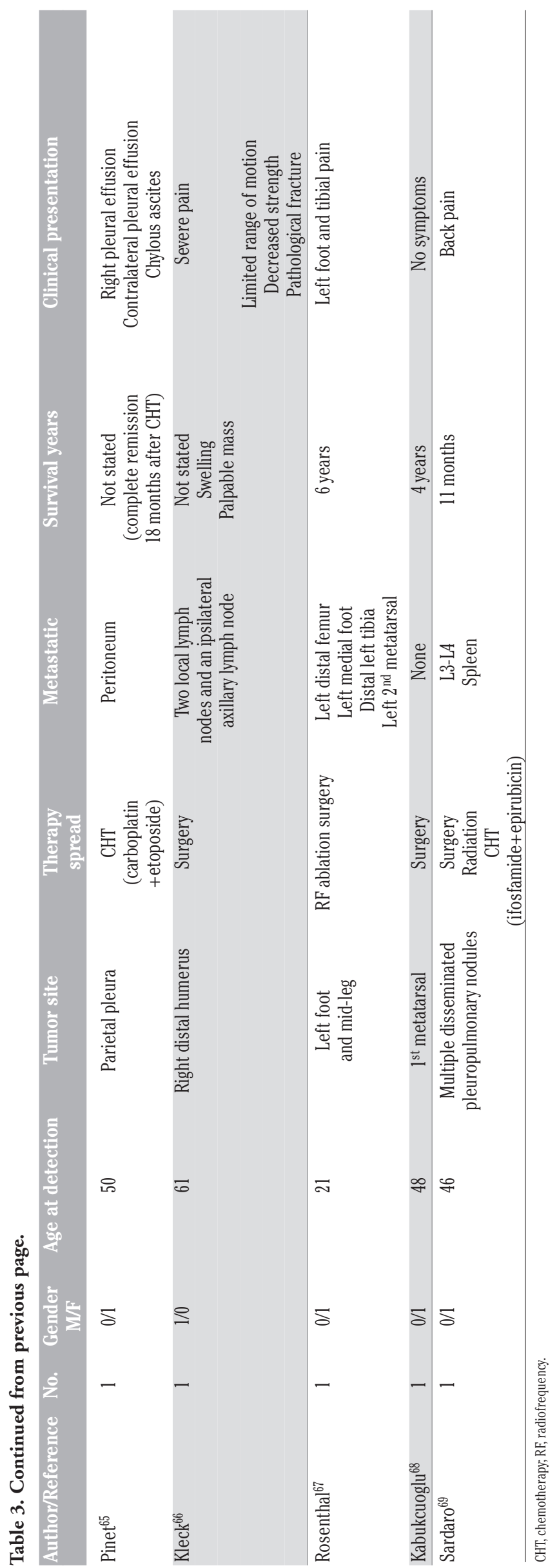

\section{Histological and cytological features}

When EHE was identified, electron microscopy showed a typical image of endothelial cells similar to those composing medium-size vessels, or a large vein, arranging in nests or cords, while immunohistochemistry revealed Weibel-Palade bodies in the cytoplasm of their cells as a typical finding. ${ }^{64}$ Table 4 describes the typical macroscopical and histolgical P-EHE appearance. ${ }^{73}$ Spindle-shaped tumor cells are occasionally present. The cell growth may form lumens of various size which occasionally contain red blood cells, that is the numerous distinct cytoplasmic vacuoles (ICLs) which may be observed under a microscope. Sometimes the ICLs are so large that the nucleus is compressed, and the cells present a signet-ring appearance. ${ }^{14,52}$ Some smears have been reported to contain cells arranged as single cells and pseudopapillary and pseudoglandular structures of varying size, or complex branching cell groups with central stromal cores, as well as cell aggregates lacking sharp anatomic borders or scalloped outlines. At the nodule's peripheral region the tumor cells extend to adjacent alveoli through the pores of Kohn, in the form of a micropolypoid growth into the lumen of respiratory and membranous bronchioles. However, the alveolar elastic framework is essentially preserved, as demonstrated by the presence of elastic tissue stains. The neoplastic tissues may invade the walls and the lumens of small pulmonary arteries, veins and lymphatic vessels. Inflammatory cellular infiltrate, congestion in the adjacent lung parenchyma and fibrin thrombosis are usually not seen. The Kitaichi's study with a detailed biological description of the $21 \mathrm{P}$ EHE patients analyzed and well categorized all these histopathological features $^{14}$ (Table 5).

\section{Immunohistochemistry}

A variety of endothelial proteins may be useful to identify EHE. The Fli-1 protein is expressed by the endothelium as well as the T-cells and megakaryocytes: this nuclear protein has proven useful in identifying vascular neoplasm including EHE, showing a better combined sensitivity and specificity than the endothelial markers CD31 and CD34. CD34 is reported to be expressed by more than $90 \%$ of vascular tumors, so this marker has poor specificity as a variety of soft tissue tumors also express it. In contrast, CD31 is regarded as a relatively specific vascular tumor marker. Some authors maintain that the combination of Fli-1 and CD31 represents an ideal panel for the differential diagnosis. ${ }^{74}$ Podoplanin is specifically expressed by lymphatic endothelial cells and has been reported to be a useful diagnostic marker to identify EHE in the liver. In addition, few cases of EHE show weak and focal positivity for cytokeratin, so cytokeratin expression does not seem to be specific for epithelial origin. ${ }^{74}$ Positive EMA and CD68 have been reported in bone EHE, ${ }^{9}$ while a case of prostatic EHE showed positive p63 and PSA plus weak patchy immunoreactivity for pankeratin (negative for urothelial markers instead, as opposed to prostatic adenocarcinoma). ${ }^{55}$ In this regard, the endothelial marker ERG is worth a mention: this is an ETS family transcription factor which is known to be expressed in endothelial cells, whose oncogenic $E R G$ gene fusions occur in subsets of prostatic adenocarcinoma, acute myeloid leukemia and Ewing sarcoma. Miettinen et al. reported ERG to be expressed over the endothelia of all of the hemangiomas, lymphangiomas and Kaposi sarcomas they analyzed, $96 \%$ of angiosarcomas and 42 of the 43 cases of EHEs they included in their study. ${ }^{75}$

\section{Prognosis and death causes}

The mean survival is 4.6 years, ranging from 6 months to 24 years. ${ }^{11,21,22}$ Gomez-Arellano et al. reported that mortality is $13 \%$ when 
EHE is located in soft tissue, $35 \%$ when it affects the liver, and $65 \%$ if it reaches the lung. According to the Kenneth Lau analysis, the 1-yearoverall survival (OS) is $90 \%$ ( $73 \%$ the 5 -year-OS), while the 1- and 5year-OS after EHE progression is 53\% and $24 \%$, respectively (median survival 1.3 years after disease progression). ${ }^{11,57}$ Asymptomatic P-EHE patients have a median survival of 180 months. Some cases of partial spontaneous regression were also reported in some asymptomatic patients. The median onset is statistically worse in case of alveolar hemorrhage, hemoptysis, hemorrhagic, pleural effusion, anemia (OS $<1$ year according to the Bagan's study). ${ }^{13}$ Patients with hilar metastases or liver involvement were also reported to have a worse prognosis, with an average survival of 2.2 years. ${ }^{17}$ EHE progresses on average in 2 years (range 0.3-22.3 years), but the presence of metastasis at the time of diagnosis does not necessarily correspond with reduced survival. Nonetheless concomitant involvement of the skeleton and viscera does not affect survival as long as it is localized and confined. Only multi-organ involvement carries a clear survival disadvantage. Conversely, we may consider the involvement of 3 or more bones and ascites as poor prognostic factors. ${ }^{11}$ All this considered, we may define the presence of pulmonary lesions, multi-organ involvement, disease progression, age $\geq 55$ years old, male patients as poor prognostic factors. Patients complaining severe respiratory symptoms (dyspnea, cough, chest pain, hemoptysis and alveolar hemorrhage), weight loss and anemia are also statistically worse, as well as those presenting pleural invasion and pleural effusion on chest X-ray at detection, extensive intravascular, endobronchial or intestinal tumor spread, hilar metastases or liver involvement, peripheral lymphadenopathy, extensive lymphangitic spread. Finally, histological finding as spindle tumor cells, fibrinous pleuritic lesions or extrapleural tumor cells proliferation show a trend towards a worse prognosis. ${ }^{4,13,14,17,19,76}$

Most patients die from respiratory failure as a result of tumor nodules increasing in size and number. In patients with bilateral disease, those with radiologic findings of alveolar hemorrhage (interstitial lesions, ground glasses opacities) and those with hemorrhagic effusion, a rapid respiratory failure is usually the cause of death. ${ }^{13} \mathrm{~A}$ small group succumbs because of extrapulmonary spread of tumor, with a predominance of liver and bone disease. ${ }^{23}$

\section{Differential diagnosis}

There are many pulmonary diseases presenting with multiple nodular lesions, including hematogenous metastases, pulmonary arteriovenous malformations, granulomatous infections and granulomatous diseases such as pulmonary hyalinizing granuloma, Wegener's granulomatosis and sarcoidosis, non-Hodgkin's lymphoma, pneumoconiosis, multiple hematomas, amyloidosis, multiple calcifying fibrous tumors (CFT).$^{22}$ Also pneumocytoma, formerly known as sclerosing hemangioma of the lung, has to be differentiated from P-EHE: it is a benign lung neoplasm and was described for the first time by Liebow and Hubbel, showing an epithelial origin with dedifferentiation of type II pneumocytes (hence the name pneumocytoma). ${ }^{77,78}$

Cytologic features, together with immunohistochemistry analysis (especially the expression of vascular endothelial markers), allow to differentiate them: negative Congo Red (different from amyloidosis), non-specific inflammatory infiltration (granulomatous disease), dense hyalinized collagenous tissue with psammomatous and lymphoplasmacitic infiltrates (CFT). ${ }^{79}$ The histologic evaluation is also necessary for differential diagnosis between EHE and other epithelioid tumors, such as adenocarcinoma (whose cytoplasmic vacuoles do not contain erythrocytes - positive for mucin stains, instead - as well as diffuse positivity for cytokeratin and epithelial membrane antigen); malignant mesothelioma (showing little cytologic atypia, two-toned cytoplasm known as fuzzy cytoplasmic borders, lack of cytoplasmic vacuoles, positivity for mesothelial markers such as calretinin, cytokeratin $5 / 6$ or WT-1); melanoma (with greater amounts of cytologic atypia and more frequent mitoses, necrotic debris and melanin pigment, and expression of S100 protein, MART-1, and other melanocytic markers); Epithelioid angiosarcoma (presenting greater cellularity, larger cells, more prominent mitotic activity, greater nuclear and nucleolar pleomorphism, and more frequent tightly, cohesive cell clusters without myxohyaline matrix, immunoreactivity for vimentin and cytokeratin); epithelioid sarcoma (negative for vascular markers); 52 meningioma (in case of intracranial localization, negative for vascular markers and positive for cytokeratin and S-100 protein). ${ }^{49}$ Sometimes EHE of bone needs to be differentiated from chordoma, chondromyxoid fibroma and myxoid chondrosarcoma, which are more voluminous and positive for S-100 protein. ${ }^{57}$

The presence of the aforementioned cytological features should prompt correlation with clinical, radiologic and histologic features (vascular differentiation), and immunochemical evaluation (vascular markers expression) so as to ensure that the diagnosis is correct. ${ }^{80}$

\section{Treatment options}

Because of its rarity EHE has no standard for treatment, and actually few therapeutic options are available. If the proposed association of Bartonella spp. infections were confirmed, it would be plausible that eradicating the bacterial infection or interrupting Bartonella-induced angiogenic and proliferative cell signals could slow the tumor progression and improve patient outcomes. ${ }^{43}$

Table 4. Pulmonary-epithelioid hemangioendothelioma histological and cytologic features.

Solitary or multiple pulmonary nodules

\begin{tabular}{ll} 
Macroscopical appearance & \\
Diameter & $>5 \mathrm{~cm}$ \\
Consistency & Rubbery or cartilage-like \\
\hline Cut surface & $\begin{array}{l}\text { From grey-white to yellow-brown } \\
\text { Semi- or normotranslucency }\end{array}$ \\
\hline Microscopical appearance & \\
Periphery of the nodules & Hypercellular \\
Centre of the nodules & Hypocellular \\
& Coagulative necrosis \\
& Hyalinization \\
& Calcification \\
& Ossification \\
\hline Cytoplasm & Abundant \\
Nucleus & Round or oval \\
\hline Atypia & Low-grade, one third marked \\
Mitotic activity & Scarce, one third notable \\
& (>10 mitosis/HPF) \\
\hline Increased risk of metastasis & Marked nuclear atypia \\
& Notable mitotic activity \\
& (>10 mitosis/HPF) \\
& Necrosis \\
\hline & \\
\hline
\end{tabular}

HPF, high-power fields. 
Table 5. Histopathological features of pulmonary-epithelioid hemangioendothelioma in 21 patients.

\begin{tabular}{|c|c|c|c|c|c|c|}
\hline Cellularity & & $\begin{array}{c}\text { Grade } 1 \\
17\end{array}$ & $\begin{array}{c}\text { Grade } 2 \\
2\end{array}$ & $\begin{array}{c}\text { Grade } 3 \\
0\end{array}$ & - & - \\
\hline Spindle tumor cells & $\begin{array}{c}\text { Grade } 0 \\
\text { Absent } \\
8\end{array}$ & $\begin{array}{c}\text { Grade } 1 \\
\text { Mild } \\
11\end{array}$ & $\begin{array}{c}\text { Grade } 2 \\
\text { Moderate } \\
2\end{array}$ & $\begin{array}{c}\text { Grade } 3 \\
\text { Marked } \\
0\end{array}$ & - & $\begin{array}{l}- \\
-\end{array}$ \\
\hline Nuclear polymorphism & & $\begin{array}{c}\text { Mild } \\
16\end{array}$ & $\begin{array}{c}\text { Moderate } \\
5\end{array}$ & $\begin{array}{c}\text { Marked } \\
0\end{array}$ & - & - \\
\hline $\begin{array}{l}\text { Necrosis of neoplasm } \\
\% \text { of necrotic changes }\end{array}$ & $\begin{array}{c}\text { Grade } 0 \\
\text { None } \\
4(19 \%) \\
\end{array}$ & $\begin{array}{c}\text { Grade } 1 \\
\text { Minimal } \\
1(5 \%)\end{array}$ & $\begin{array}{c}\text { Grade } 2 \\
<25 \% \\
3(14 \%)\end{array}$ & $\begin{array}{l}\text { Grade } 3 \\
25-50 \% \\
2(10 \%) \\
\end{array}$ & $\begin{array}{l}\text { Grade } 4 \\
50-75 \% \\
6(29 \%) \\
\end{array}$ & $\begin{array}{c}\text { Grade } 5 \\
>75 \% \\
5(24 \%) \\
\end{array}$ \\
\hline
\end{tabular}

The available treatment options are mentioned in Tables 1 and 3. When the lesions are small and limited in number, some authors recommend surgical resection or an preventive approach to asymptomatic patients. Successful curative resection achieves good outcomes. The role of adjuvant chemotherapy and/or radiation therapy (RT) is ambiguous, instead. Usually RT after surgical resection is chosen for localized EHE, in order to control the residual disease given the recurrence of EHE, while chemotherapy is preferred in case of widespread disease. However, their beneficial effect is still not confirmed. $4,14,17,23,65$

\section{Lung}

In patients with unilateral P-EHE nodules, wedge resection offers the same survival outcomes as anatomic resection does. Hilar lymph node resection should be systematically proposed, but the prognostic value of lymph node invasion remains statistically unclear because of the low number of patients with lymph node metastases. ${ }^{13}$ Conversely, a complete surgical resection is usually impossible for pleural EHE. Pinet $e t$ al. reported a case of an aggressive form of pleural EHE resulting in complete remission after treatment with carboplatin plus etoposide. ${ }^{65}$ In patients with bilateral nodules, partial or complete response has been reported using interferon 2 (showing anti-angiogenic properties), and some partial spontaneous regression has also been described. ${ }^{18}$ Corticosteroids, azathioprine, multiple wedge resections or simple follow up are the other proposed treatment options. Multiple chemotherapeutic regimens (MAID) have been tried, but no improvement has been reported. Given its vascular origin, angiogenesis inhibition may be a reasonable approach for the management of metastatic EHE. The available literature reported good tolerance and stabilization of an aggressive, metastatic P-EHE using bevacizumab and nanoparticle albumin-bound paclitaxel (nab-paclitaxel): one partial response, one stable disease (that was the only EHE of bone $v$ s five P-EHE), and four progression disease (PD) of six patients treated using bevacizumab combined with MAID. ${ }^{24}$ In contrast, the use of thalidomide for nonthoracic EHE led to two partial responses, one stable disease and two PD of five treated patients, while using lenalidomide alone resulted in stable disease at the 48 -month follow up. ${ }^{24}$

\section{Liver}

Locally advanced hepatic EHE seems to benefit from transplantation, with good results. ${ }^{63}$

\section{Bone}

Radical surgery is performed for resectable bone tumors, followed by joint reconstruction. En-bloc resection is preferred in case of solitary lesions; amputation is necessary for multicentric lesions. When a pathological fracture occurs, temporary internal stabilization with a plate and screws for pain control is chosen. ${ }^{66} \mathrm{~A}$ great alternative in the last case is radiofrequency ablation: the aim is to create small thermal injuries of bone carefully controlled, so that the extent of resection is reduced with a better esthetic result as amputation can be avoided. ${ }^{67}$

\section{Radiation therapy}

This therapeutic option has proven to be ineffective for P-EHE because of the tumor's slow growth and consequently of its radiobiological characteristics, while a good local control has been obtained in EHE with exclusive bone presentation when RT was combined with bone surgery, especially if the lesions are not surgically accessible..$^{23,64}$

Since EHE has been correctly defined, there have been several research groups dealing with EHE irradiation. A 4000 cGy for 4 weeks protocol, and later a 3000 cGy course of RT towards the spine after surgical removal of EHE of vertebrae have been described. ${ }^{23,64}$ The aim was avoiding local recurrences: 1 case survived 11 years, the remaining ones experienced a worsening due to multiple hepatic and abdominal metastases. Thereafter, a 6400 cGy adjuvant RT was performed against an axillary form of EHE, resulting in the absence of lymph nodes metastases but pleural and pulmonary widespread. ${ }^{17} \mathrm{~A}$ local irradiation after surgical resection of EHE of bone, based on 6000 cGy in 23 fractions for 43 days, showed a good tolerance of the treatment, either regional nor distant metastases or local recurrence at 6, 12 and 24 month-followup. ${ }^{61}$ A protocol of 33 fractions of RT, totaling $5940 \mathrm{cGy}$, was recently applied to residual, postoperative mastoid: eight years after surgery and adjuvant RT, imaging has demonstrated neither recurrence nor changes in patient's clinical exam. ${ }^{47}$ RT may be used above all in an attempt to sclerose the blood vessels, in any case the use of radiation must be carefully considered in the pediatric age, as RT increases the risk of secondary sarcoma. ${ }^{68}$

\section{Conclusions}

Except for P-EHE, taking into account the extremely variable EHE occurrence and its radiobiological characteristics, RT seems to carve out a significant role in the treatment of such a complex and extremely rare disease.

The available literature reveals no consensus about the radiation dose to be used for the locoregional control of EHE: is this attributable to the very small number of patients and to the limited survival that EHE typically shows? Further studies are needed to answer the question. Actually, no doubt evidence is all in favor of RT obtaining local pain control with good tolerance and better quality of life at least at one-year-follow up. 


\section{References}

1. Dail DH, Liebow AA. Intravascular bronchioloalveolar tumor. Am J Pathol 1975;78:6a-7a.

2. Wong DSY, TW Chiu, Burd ADR, et al. Epithelioid hemangioendothelioma of the anterior skull base: what is the optimal treatment? Hong Kong Med J 2009;15:308-10.

3. Tsarouha H, Kyriazoglou AI, Pandis N, et al. Chromosomal analysis and molecular cytogenetic investigations of an epithelioid hemangioendothelioma. Cancer Genet Cytogenet 2006;169:164-8.

4. Dail DH, Liebow AA, Gmelich JT, et al. Intravascular, bronchiolar, and alveolar tumor of the lung (IVBAT). An analysis of twenty cases of a peculiar sclerosing endothelial tumor. Cancer 1983;51:452-64.

5. Weiss SW, Enzinger FM. Epithelioid hemangioendothelioma: a vascular tumor often mistaken for a carcinoma. Cancer 1982;50:970-81.

6. Weiss SW, Ishak KG, Enzinger FM, et al. Epithelioid hemangioendothelioma and related lesions. Semin Diagn Pathol 1986;3:259-87.

7. Corrin B, Manners B, Weaver L, et al. Histogenesis of the so-called 'intravascular bronchioloalveolar tumor'. J Pathol 1979;123:163-7.

8. Weldon-Linne CM, Victor TA, Fry WA, et al. Angiogenic nature of the intravascular bronchioloalveolar tumor of the lung: an electron microscopic study. Arch Pathol 1981;105:174-9.

9. Mertens F, Unni K, Fletcher CDM. World Health Organization classification of tumors. Pathology and genetics. Tumors of soft tissue and bone. Lyon: IRAC Press; 2002. p 155.

10. Mukherjee S, Mallick J, Chattopadhyay $\mathrm{S}$, et al. Hemangioendothelioma of soft tissue: Cytological dilemma in two unusual sites. J Cytol 2012;29:89-91.

11. Lau K, Massad M, Weinberg G, et al. Clinical patterns and outcome in epithelioid hemangioendothelioma with or without pulmonary involvement. Chest 2011;140:1312-8.

12. Amin RM, Hiroshima K, Kokubo T, et al. Risk factors and independent predictors of survival in patients with pulmonary epithelioid hemangioendothelioma. Review of the literature and a case report. Respirology 2006;11:818-25.

13. Bagan P, Hassan M, Riquet M, et al. Prognostic factors and surgical indications of pulmonary epithelioid hemangioendothelioma: a review of the literature. Ann Thorac Surg 2006;82:2010-3.

14. Kitaichi M, Nagai S, Dail DH, et al. Pulmonary epithelioid hemangioendothelioma in 21 patients, including three with partial spontaneous regression. Eur Respir J 1998;12:89-96.

15. Rock MJ, Kaufman RA, Moss ML, et al. Epithelioid hemangioendothelioma of the lung (intravascular bronchioloalveolar tumor) in a young girl. Pediatr Pulmonol 1991;11:181-6.

16. Einsfelder B, Kuhnen C. Epithelioid hemangioendothelioma of the lung (IVBAT) - clinicopathological and immunohistochemical analysis of 11 cases (in German). Pathologe 2006;27:106-15.

17. Schattenberg T, Kam R, Pfannschmidt J, et al. Pulmonary epithelioid hemangioendothelioma: report of three cases. Surg Today 2008;38:844-9.

18. Radzikowska E, Szczepulska-Wójcik E, Roszkowski K, et al. Pulmonary epithelioid hemangioendothelioma - interferon 2-alpha treatment - case report. Pneumol Allergol Pol 2008;76:281-5.

19. Ye B, Wang L, Mao Y-S, et al. Multiple organ metastases of pulmonary epithelioid hemangioendothelioma and a review of the literature. Med Oncol 2010;27:49-54.

20. Sicilian L, Warson F, Gaensler EA et al. Intravascular bronchioloalveolar tumor (IVBAT): case report. Respiration 1983;44:387-94.

21. Teo SK, Chiang SC, Tan KK. Intravascular bronchioloalveolar tumor: a 20 year survival. Med J Aust 1985;142:220.

22. Miettinen M, Collan Y, Vilkko P, et al. Intravascular bronchioloalveolar tumor. Cancer 1987;60:2471-5.
23. van Kasteren MEE, van der Wurff AAM, Miseré JFMM, et al. Epithelioid hemangioendothelioma of the lung: clinical and pathological pitfalls. Eur Respir J 1995;8:1616-9.

24. Gaur S, Torabi A, O'Neill TJ. Activity of angiogenesis inhibitors in metastatic epithelioid hemangioendothelioma: a case report. Cancer Biol Med 2012;9:133-6.

25. Nakatani Y, Aoki I, Misugi K. Immunohistochemical and ultrastructural study for early lesions of intravascular bronchioloalveolar tumor with liver involvement. Acta Pathol Jpn 1985;35:453-65.

26. Yanagawa H, Hashimoto Y, Nagano T, et al. Intravascular bronchioloalveolar tumor with skin metastases. Chest 1994;105:1882-4.

27. Coulibaly B, Tasei AM, Figarella-Branger D, et al. Pulmonary epithelioid hemangioendothelioma: two different clinical courses. Monaldi Arch Chest Dis 1999;54:231-3.

28. Hanada N, Namai S, Katagiri M, et al. Case report of pulmonary epithelioid hemangioendothelioma (in Japanese). Nihon Kokyuki Gakkai Zasshi 2003;41:144-9.

29. Cronin P, Arenberg D. Pulmonary epithelioid hemangioendothelioma: an unusual case and a review of the literature. Chest 2004;125:789-93.

30. Sakamoto N, Adachi S, Hanioka K, et al. High resolution CT findings of pulmonary epithelioid hemangioendothelioma: unusual manifestations in 2 cases. J Thorac Imaging 2005;20:236-8.

31. Iwashima D, Kobayashi J, Takashima Y, et al. A case of pulmonary epithelioid hemangioendothelioma detected on medical checkup. Nihon Kokyuki Gakkai Zasshi 2005;43:595-9.

32. Chen TM, Donington J, Upadhyay D, et al. Recurrence of pulmonary intravascular bronchoalveolar tumor with mediastinal metastasis 20 years later. Respir Med 2006;100:367-70.

33. Carretero A, Elmberger PG, Collins BT, et al. Pulmonary epithelioid hemangioendothelioma: report of a case with fine needle aspiration biopsy. Acta Cytol 2006;50:455-9.

34. Anagnostou V, Mossa E, Tiniakos DG, et al. Epithelioid hemangioendothelioma of the lung presenting with pulmonary nocardiosis. In Vivo 2007;21:1123-6.

35. Saleiro S, Barbosa M, Ferreira S, et al. Epithelioid hemangioendothelioma - a rare pulmonary tumor. Rev Port Pneumol 2008;14:4215.

36. Bahrami A, Allen TC, Cagle PT. Pulmonary epithelioid hemangioendothelioma mimicking mesothelioma. Pathol Int 2008;58:730-4.

37. Kpodonu J, Tshibaka C, Massad MG. The importance of clinical registries for pulmonary epithelioid hemangioendothelioma. Chest 2005;127:1870-1.

38. Lee YJ, Chung MJ, Kim JT. Pleural epithelioid hemangioendothelioma. Yonsei Med J 2008;49:1036-40.

39. Gordillo GM, Onat D, Stockinger M, et al. A key angiogenic role of monocyte chemoattractant protein-1 in hemangioendothelioma proliferation. Am J Physiol Cell Physiol 2004;4:C866-73.

40. Budousquie AC, Lawee HJ, Sherman R, et al. Complex translocation $(7 ; 22)$ identified in an epithelioid hemangioendothelioma. Cancer Genet Cytogenet 1996;92:116-21.

41. Errani C, Zhang L, Antonescu CR, et al. A novel WWTR1-CAMTA1 gene fusion is a consistent abnormality in epithelioid hemangioendothelioma of different anatomic sites. Genes Chromosomes Cancer 2011;50:644-53.

42. Antonescu CR, Le Loarer F, Mosquera JM, et al. Novel YAP1-TFE3 fusion defines a distinct subset of epithelioid hemangioendothelioma. Genes Chromosomes Cancer 2013;52:775-84.

43. Mascarelli PE, Iredell JR, Breitschwerdt EB, et al. Bartonella species bacteremia in two patients with epithelioid hemangioendothelioma. J Clin Microbiol 2011;49:4006-12.

44. Boscaino A, Errico ME, De Rosa G, et al. Epithelioid hemangioendothelioma of the larynx. Tumori 1999;85:515-8.

45. Silva EG, Philips MJ, Ordonez NG, et al. Spindle and histiocytoid 
(epithelioid) hemangioendothelioma. Primary in lymph node. Am J Clin Pathol 1986;85:731-5.

46. Napaki S, Stirling JW. Spindle and epithelioid (histiocytoid) hemangioendothelioma of cervical lymph nodes. Pathology 2004;36:587-9.

47. Drazin D, Gandhi R, Boulos AS, et al. Epithelioid hemangioendothelioma of the mastoid: resection for recurrence and adjuvant radiation with 8-year follow up. Case Rep Surg 2013;2013:469201.

48. Baehring JM, Dickey PS, Bannykh SI. Epithelioid hemangioendothelioma of the suprasellar area: a case report and review of the literature. Archiv Pathol Lab Med 2004;128:1289-93.

49. Ma S-R, Li K-C, Li Q, et al. Primary epithelioid hemangioendothelioma in the clival region: a case report and literature review. Neuropathology 2011;31:519-22.

50. Tammam AG, Lewis PD, Crockard HA. Cerebellopontine angle epithelioid hemangioendothelioma in a 4-year-old boy. Child's Nervous System 1997;13:648-50.

51. Kerry G, Marx 0, Steiner HH, et al. Multifocal epithelioid hemangioendothelioma derived from the spine region: case report and literature review. Case Rep Oncol 2012;5:91-8.

52. Murali R, Zarka MA, Tazelaar HD, et al. Cytologic features of epithelioid hemangioendothelioma. Am J Clin Pathol 2011;136:739-46.

53. Iimuro Y, Nakai N, Fujimoto J, et al. Primary epithelioid hemangioendothelioma of the retroperitoneum: report of a case. Surg Today 2012:42:1026-31.

54. Illueca C, Machado I, Almenar S, et al. Uncommon vascular tumor of the ovary. Primary ovarian epithelioid hemangioendothelioma or vascular sarcomatous transformation in ovarian germ cell tumor?. Arch Gynecol Obstet 2011;284:1589-91.

55. Iyer A, Thompson L, Cooper K. Epithelioid hemangioendothelioma, mimicking prostatic adenocarcinoma. Histopathology 2011;60:51127.

56. Al-Faky YH, Al Malki S, Raddaoui E. Hemangioendothelioma of the eyelid can mimic chalazion. Oman J Ophthalmol 2011;4:142-3.

57. Gomez-Arellano LI, Ferrari-Caballo T, Dominguez-Malagon HR. Multicentric epithelioid hemangioendothelioma of bone. Report of a case with radiologic-pathologic correlation. Annals Diagn Pathol 2012;16:43-7.

58. de Singly B, Pommaret E, Coriat R, et al. Colonic metastases of an epithelioid hemangioendothelioma: an unusual cause of periumbilical pain and wheight loss. Dig Liver Dis 2011;43:e10.

59. Christopher DM, Fletcher CDM, Mertens F, et al. Pathology and genetics of tumours of soft tissue and bone. Lyon: International Agency for Research on Cancer (IARC) Press; 2002.

60. Larochelle 0 , Périgny $M$, Giguère $C$, et al. Best Cases from the AFIP - epithelioid hemangioendothelioma of bone. RadioGraphics 2006;26:265-70.

61. Gherman CD, Fodor D. Epithelioid hemangioendothelioma of the forearm with radius involvement. Case report. Diagn Pathol 2011;6:120.

62. Vidya Lakshmi S, Prabhavathy D, Tharini GK, et al. Epithelioid hemangioendothelioma: a rare vascular tumor. Indian J Dermatol 2012;57: 53-4.
63. Kim SJ, Kim YC. Unusual extrahepatic metastasis to the soft tissue of the left cervical neck area from hepatic epithelioid hemangioendothelioma. Hepatology 2011;54:1480-1.

64. Aquilina K, Lim C, Keohane C, et al. Epithelioid hemangioendothelioma of the spine. J Neurosurg Spine 2005;3:393-9.

65. Pinet C, Magnan A, Vervloet D, et al. Aggressive form of pleural epithelioid hemangioendothelioma: complete response after chemotherapy. Eur Respir J 1999;14:237-8.

66. Kleck CJ, Seidel MJ. Epithelioid hemangioendothelioma of the distal humerus with pathologic fracture. Orthopedics 2012;35:e116-9.

67. Rosenthal DI, Treat ME, Jennings CL, et al. Treatment of epithelioid hemangioendothelioma of bone using a novel combined approach. Skeletal Radiol 2001;30:219-22.

68. Kabukcuoglu F, Kabukcuoglu Y, Kuzgun U, et al. Epithelioid hemangioendothelioma of bone. Acta Orthop Traumatol Turc 2006;400:324-8.

69. Sardaro A, Bardoscia L, Angelelli G, et al. Pulmonary epithelioid hemangioendothelioma presenting with vertebral metastases: a case report. J Med Case Rep 2014;8:201.

70. Rest CC, Botton E, Visvikis D, et al. FDG PET in epithelioid hemangioendothelioma. Clin Nucl Med 2004;29:789-92.

71. Ergun EL, Lim E. Increased FDG uptake in pulmonary epithelioid hemangioendothelioma. Rev Esp Med Nucl 2006;25:188-92.

72. Watanabe S, Yano F, Sakata I, et al. 18F-FDG-PET/CT as an indicator for resection of pulmonary epithelioid hemangioendothelioma. Ann Nucl Med 2008;22:521-4.

73. Deyrup AT, Tighiouart M, Weiss SW, et al. Epithelioid hemangioendothelioma of soft tissue: a proposal for risk stratification based on 49 cases. Am J Surg Pathol 2008;32:924-7.

74. Gill R, O'Donnell RJ, Horvai A. Utility of immunohistochemistry for endothelial markers in distinguishing epithelioid hemangioendothelioma from carcinoma metastatic to bone. Arch Pathol Lab Med 2009;133:967-72.

75. Miettinen ML, Wang ZF, Sesterhenn I, et al. ERG transcription factor as an immunohistochemical marker for vascular endothelial tumors and prostatic carcinoma. Am J Surg Pathol 2011;35:432-41.

76. Liu Q, Miao J, Lian K, et al. Multicentric epithelioid hemangioendothelioma involving the same lower extremity: a case report and review of literature. Int J Med Sci 2011;8:558-63.

77. Ruiz de la Cuesta D, Lafont Rufat M, Ruiz de la Cuesta Martín E. Pneumocytoma (formerly known as sclerosing hemangioma of the lung): a rare cause of chest pain. Arch Bronconeumol 2013;49:2767.

78. Gupta M, Shah J, Rao VM, et al. Case of pulmonary pneumocytoma: a probable cytological diagnosis with histopathological confirmation. Indian J Pathol Microbiol 2014;57:89-91.

79. Xu J, Lirong C. Pulmonary epithelioid hemangioendothelioma accompanied by bilateral calcified nodules in lung. Diagn Pathol 2011;6:21.

80. Hristov AC, Wisell J. A "high-risk" epithelioid hemangioendothelioma presenting as a solitary, ulcerated, subcutaneous tumor. Am J Dermatopathol 2011;33:88-90. 